\title{
Characterization and fluoride uptake studies of nano-scale iron oxide-hydroxide synthesized by microemulsion method
}

\author{
M. G. Sujana*, S. Mohanty \\ Institute of Minerals and Materials Technology (CSIR), Bhubaneswar, INDIA \\ *Corresponding Author Email id: mgsujana@gmail.com
}

\begin{abstract}
In the present study nano scale iron oxide hydroxide was synthesized by water in oil microemulsion method. A non-ionic surfactant span 80 , hexanol and $\mathrm{FeCl}_{3}$ were chosen as starting materials. The prepared sample was characterized by XRD, TEM, TGA and FT-IR. X-ray diffraction pattern showed it be 2- line ferrihydrite like structure. TEM showed aggregated particles in the range of 5-10 nm size. The fluoride adsorption efficiency of the nano powder was determined with respect to contact time, initial $\mathrm{F}^{-}$concentration and $\mathrm{pH}$ of the solution. The batch adsorption data revealed that the fluoride adsorption efficiency was highly influenced by the studied factors. Equilibrium was attained within one hour of contact time indicating fast kinetics. The adsorption data followed second order kinetic model. The isothermic data fitted to both Langmuir and Freundlich models and maximum loading capacity as estimated by Langmuir model was $62.89 \mathrm{mg} / \mathrm{g}$ for the studied concentration range of 10-30 mg/L. The high loading capacity points towards the potential of this adsorbent for fluoride removal from aqueous streams.
\end{abstract}

Keywords: Fluoride, nano-iron oxide hydroxide, adsorption, kinetics, isotherm study.

\section{Introduction}

Fluoride exists in many forms, and the harmful nature of the fluoride is contingent upon the type of fluoride it is. Depending on its concentration, the fluoride in drinking water is known for both beneficial and detrimental effects on health, particularly to infants and young children. The toxicity of fluoride on human health is well documented (www.unicef.org/wes/files/fluoride.pdf.). The WHO specified tolerance limit for fluoride in drinking water in most of the countries is less than $1 \mathrm{mg} / \mathrm{L}$, these guideline value for fluoride in water is not universal. According to the WHO (1984) guidelines and recommendations in the areas with a warm climate, the optimal fluoride concentration in drinking water should remain below $1 \mathrm{mg} / \mathrm{L}(1 \mathrm{ppm})$, while in cooler climates it could go up to $1.2 \mathrm{mg} / \mathrm{L}$. The differentiation derives from the fact that people perspire more in hot weather and consequently drink more water (WHO 1996). Indian standards for drinking water recommended maximum permissible limit of $1 \mathrm{mg} / \mathrm{L}$ and the maximum tolerance limit as $1.5 \mathrm{mg} / \mathrm{L}$ for potable water by World Health Organization (WHO 2004, BIS, 2003 IS:10500 ).

The conventional approaches for fluoride removal include chemical precipitation, ion exchange, adsorption, electro-dialysis, Donnan dialysis and reverse osmosis (Hichour et al., 2000; Lou and Inoue, 2004; Ndiaye et al., 2005; Biswas et al., 2007; Sujana et al., 2009). Among all these methods, adsorption technique is economically favourable and technically feasible to separate fluoride from aqueous solutions as the requirement of operative controls are minimal (Raichur and Basu, 2001).

Activated alumina is one of the most widely used adsorbents for fluoride removal in the drinking water treatment (Choi and Chen, 1979; Wu and Nitya, 1979) due to its high affinity, resulting from the cause that the aluminum ion can form inner-sphere complexation. However, because of the high cost for the method of activation and low sorption capacity of activated alumina there is a necessity to develop adsorbent with enhanced adsorption capacity for application. These days use of nanoparticles is becoming very attractive in the area of adsorption or recovery of metal ions from industrial wastes or natural water streams. During the past few years, iron based novel sorbent with strong affinity towards fluoride have been developed for fluoride removal (Wei et al., 2006; Chiung-Fen et al., 2006; Lin Chen et al., 2009; Xiaoli Zhao et al., 2010). 
Preparation of iron oxides in nano range is by no means a new research subject; however, practical methods are still needed for synthesizing high quality ultra fine powders with required characteristics in terms of their size, uniformity, morphology, specific surface areas, crystallinity etc.. Numerous techniques have been proposed to synthesize nano-sized $\mathrm{Fe}_{2} \mathrm{O}_{3}$ particles with promising control of properties, such as wet chemical method (Jiye fang et al., 2003), hydrothermal (Song et al., 2009), pyrolysis (Dghoughi et al., 2006), sol gel (Markus Niederberger, 2007). The reverse micelle or water in oil (w/o) micro emulsions has received considerable attention for preparing nano- sized particles. Once the right micro emulsions are obtained the method of particle preparation consists in mixing of two microemulsions carrying the appropriate reactants in order to obtain the desired particles. Alternatively dilute $\mathrm{NH}_{4} \mathrm{OH}$ can simply be added directly to a clear, transparent microemulsion solution of the metal ions. By following this method, several studies have been carried out in recent years. Preparation of catalysts from micro emulsions and their applications in heterogeneous catalysts are well reviewed (Sara Eriksson et al., 2004).

This article describes the synthesis of iron oxide nanoparticles by water in oil microemulsion of water/span $80 / \mathrm{n}$-hexanol by simple co-precipitation method. Co-precipitation was carried out by direct addition of ammonia solution as precipitant at room temperature. The particle size and structural properties of the prepared nano powder have been characterized by Transmission Electron Microscopy (TEM), X-ray diffraction studies, FT-IR and Thermo gravimetric analysis. The fluoride adsorption efficiency of the nano iron oxide-hydroxide particles was examined by conducting batch mode experiments.

\section{Materials and Methods}

\subsection{Preparation and characterization}

Iron hydroxide nano particles were prepared by micro emulsion mediated synthesis process. The chemicals used in this synthesis process were ferric chloride, $30 \%$ ammonia, n-hexanol, span 80 and acetone. All the chemicals were of analytical grade and were used with out any further purification. To select a proper compositional range that would form a microemulsion in the water/span 80/n-hexanol system the titration method was applied (Rabie et al., 1997). The microemulsion was prepared by taking water/ n-hexanol/span 80 in the volumetric ratio of 5.5:90:4.5. To a mixture of n-hexanol and span 80 required amount of $1 \mathrm{M} \mathrm{FeCl} 3$ solution was added very slowly. During the addition, the contents were being stirred constantly with a magnetic stirrer at room temperature. After a few minutes, the mixture became transparent indicating formation of microemulsion. This microemulsion was admixed with an appropriate amount of aqueous ammonia solution at room temperature. The precipitation continued till the $\mathrm{pH}$ of the solution reached 10 and the contents were allowed to stir for 30 minutes more and allowed to settle. The dark brown colored precipitate was separated by centrifuging at $5000 \mathrm{rpm}$, washed repeatedly with double distilled water and acetone to remove other impurities. The synthesized powder was dried at $60^{\circ} \mathrm{C}$ for $24 \mathrm{~h}$ and stored in an air tight container for further use.

The XRD analyses of the samples were taken using P Analytical (model-X' pert PRO PW-3040/60 with Mo $\mathrm{K}_{\alpha}$ radiation at a scan speed of $1.2^{\circ} \mathrm{min}^{-1}$ over a range of 5 to $50^{\circ}$. The TEM analysis of the sample was carried out on Transmission Electron Microscope, model TECNAI G ${ }^{2}$, FEI, Netherland. For Fourier transform infrared (FT-IR) spectra Varian-Australia, Model 800 spectrophotometer was used. The weight loss measurements were carried out thermo gravimetrically (TG, Metler Toledo TGA/SDTA 821e, Switzerland) in dry air at a heating rate of $20^{\circ} \mathrm{C} / \mathrm{min}$. All the $\mathrm{pH}$ measurements were carried out by Consort digital $\mathrm{pH}$ meter (231). The $\mathrm{pH}_{\mathrm{pzc}}$ of prepared sample was determined by solid addition method adopted by Balistrieri and Murray, (1981). Accordingly, to a series of well-stoppered $125 \mathrm{ml}$ polyethylene bottles containing $40 \mathrm{ml}$ of $0.01 \mathrm{M} \mathrm{KNO}_{3}$ electrolyte solution, different volumes of either $0.1 \mathrm{M} \mathrm{HCl}$ or $0.1 \mathrm{M} \mathrm{NaOH}$ solution were added to obtain wide-ranging pH values from 3 to 8 . The total volume of solution in each bottle was made up to $50 \mathrm{~mL}$ by addition of distilled water. After $2 \mathrm{~h}$ of equilibration the $\mathrm{pH}$ values $\left(p H_{i}\right)$ were noted and $0.2 \mathrm{~g}$ of sample was added. After $72 \mathrm{~h}$ of equilibration at room temperature $(305 \pm 3 \mathrm{~K})$ with intermittent shaking, the $\mathrm{pH}$ value of the supernatant liquid in each bottle was noted $\left(p H_{f}\right)$. The difference between $p H_{i}$ and $p H_{f}$ $(\triangle p H)$ were then plotted against $\mathrm{pH}_{\mathrm{i}}$, The solution $\mathrm{pH}$ at which $\triangle p H=0$ is "the $p H_{p z c}$ of the sample. Fluoride analysis was carried out by following SPADNS method (APHA, 1987). A known volume of sample was taken in a $25 \mathrm{~mL}$ polypropylene volumetric flask and $5 \mathrm{~mL}$ of SPADNS reagent was added. The volume was made into $25 \mathrm{~mL}$ using double distilled water, allowed to stand for $15 \mathrm{~min}$ for complete colour development and the absorbance was measured at $570 \mathrm{~nm}$ using Thermo, Water Analyzer Spectrophotometer Model AquaMate.

\subsection{Batch adsorption experiments}

A $100 \mathrm{mg} / \mathrm{L}$ fluoride stock solution was prepared by dissolving $0.221 \mathrm{~g}$ of NaF in $1 \mathrm{~L}$ of double distilled water. The experimental solutions were prepared by appropriate dilutions of the above solution. $0.025 \mathrm{~g}$ of the sample was taken in a $100 \mathrm{~mL}$ polyethylene plastic vial and $50 \mathrm{~mL}$ of fluoride solution of known concentration was added. The contents were kept for constant shaking in a temperature controlled Julabo water bath shaker over a period of time and the solids were separated by centrifuging at $5000 \mathrm{rpm}$ on REMI centrifuge. The solutions were collected for analysis and fluoride concentration in the solutions was determined. The adsorption capacity $\mathrm{X}(\mathrm{mg} / \mathrm{g})$ of the adsorbent was calculated from the following equation $X=\left(C_{i}-C_{e}\right) / C_{A}$; where $C_{e}$ is the residual concentration reached at equilibrium state, $C_{i}$ is initial fluoride concentration and $C_{A}$ is the adsorbent concentration. 


\section{Results and Discussion}

\subsection{Characterization}

XRD patterns of precursor sample is shown in Figure 1. The uncalcined sample is iron oxide hydroxide, amorphous in nature and showed two small peaks at $2 \theta$ value of 16.25 and 27.75 with the corresponding ' $d$ ' spacing value of 2.5032 and 1.4789 (these values correspond to 2-line ferrihydrite like structure and matching with JCPDS File No 29-0712).

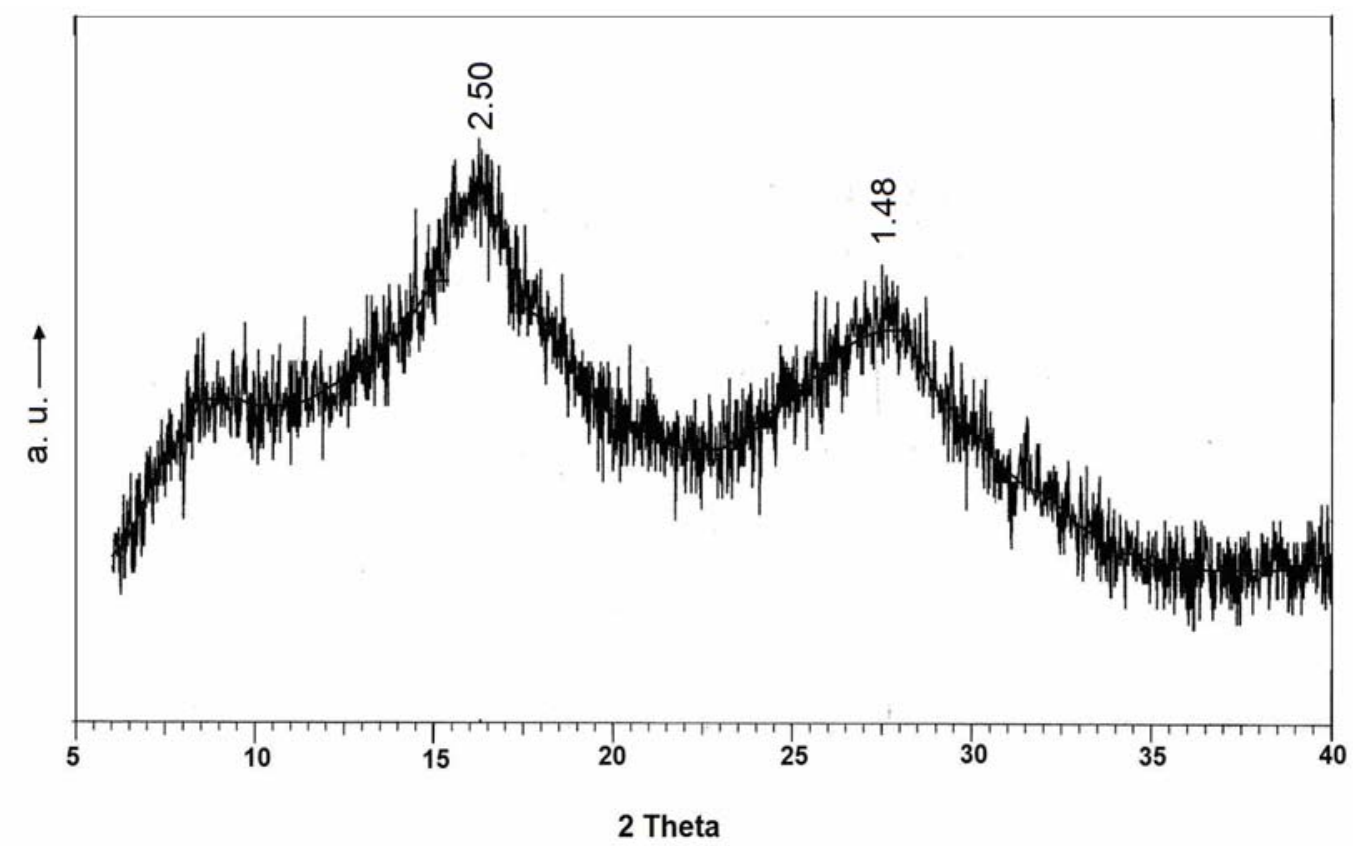

Figure 1. XRD patterns of iron oxide hydroxide nano particle synthesized by w/o microemulsion method at room temperature.

The FT-IR spectrum of the sample shows a number of sharp and small bands (Figure 2). The presence absorption bands at 640, 574 and $433 \mathrm{~cm}^{-1}$ corresponds to the Fe-O bond (Yamaura et al., 2004). The bands at 3554, 2933, 2388, 1543, 1402 and $771 \mathrm{~cm}^{-1}$ indicate the presence of water molecules and residual surfactant molecules interaction with iron oxyhydroxide nano particles (Yuan-hu Zhang et al., 2006).

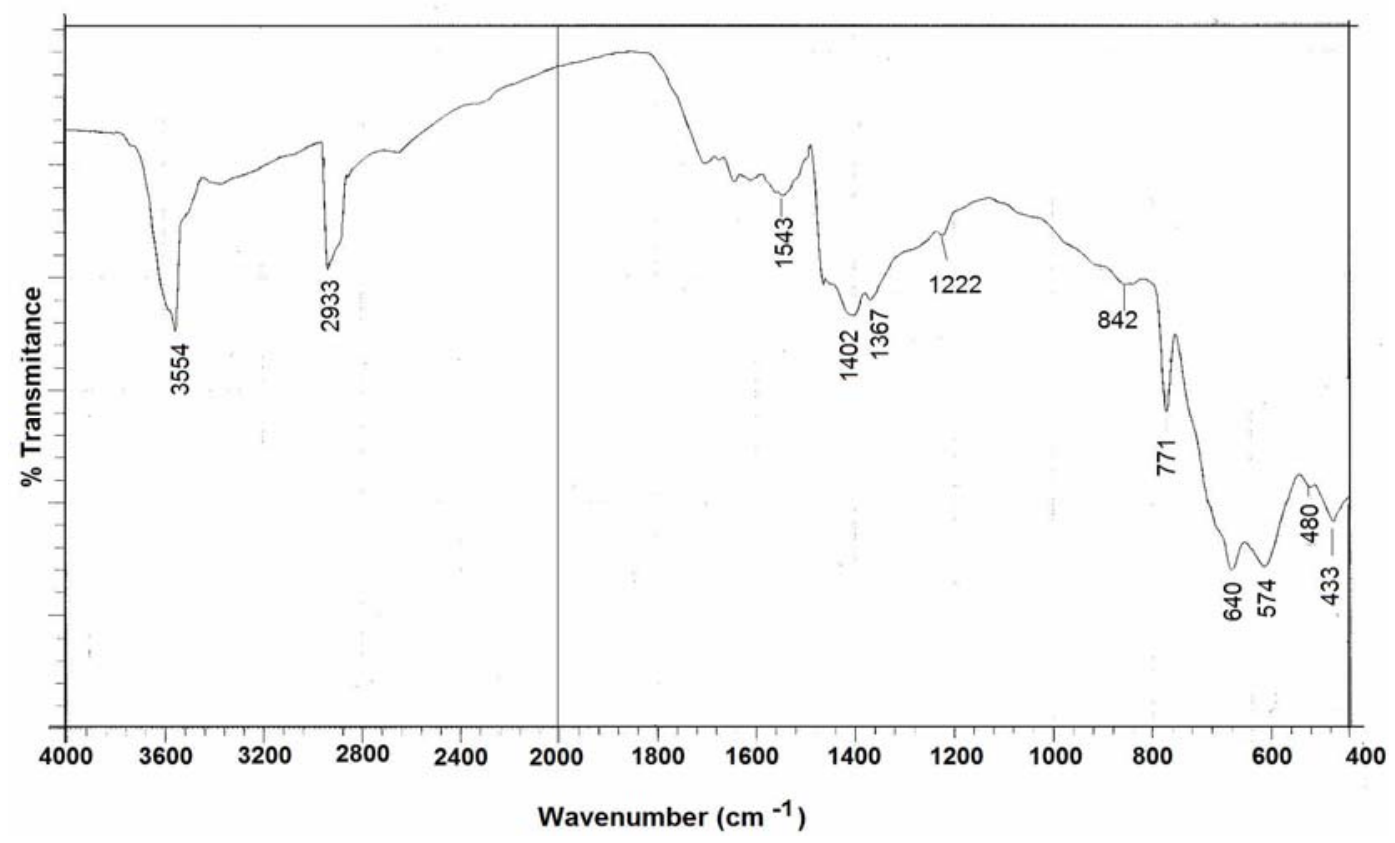

Figure 2. FT-IR spectra of the prepared iron oxide hydroxide sample. 
Figure 3 shows TGA of the ferrihydrite sample prepared through microemulsion route. The weight loss of the sample can be seen mainly in three stages. The first stage is from 60 to $220^{\circ} \mathrm{C}$, mostly due to the evaporation of physically bound water and surfactant from the surface of the sample. The abrupt weight loss between $220-360^{\circ} \mathrm{C}$ can be regarded as the thermal decomposition of ferrihydrite to $\gamma-\mathrm{Fe}_{2} \mathrm{O}_{3}$. The third weight loss observed in between 360 to $450^{\circ} \mathrm{C}$ is very sharp and may be associated with the decomposition of the residual surfactant. (Jin Qiu et al., 2005). The broad endothermic peak in the range of $100-140^{\circ} \mathrm{C}$ correspond to the loss of physically bound water (Balek, and Subrt., 1995). Another endo peak observed at $380^{\circ} \mathrm{C}$ may due to complete dehydration of ferrihydrite to crystalline $\mathrm{Fe}_{2} \mathrm{O}_{3}$. Part of the weight loss could be due to decomposition of surfactant. Similar observations were reported for mesoporous gamma iron oxide nano particles prepared by microemulsion method using heptanewater - CTAB system (Petrova et al., 2006).

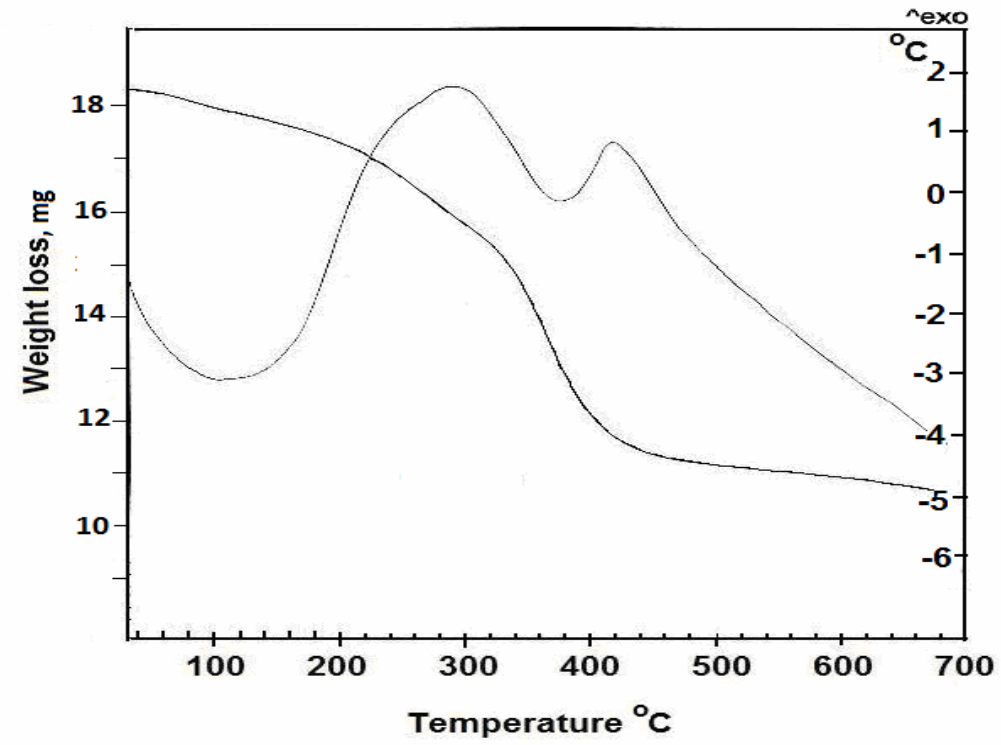

Figure 3. Thermogravimetric analysis of the iron oxide hydroxide nano particles.

The Transmission Electron Microscope images of the sample dried at $60^{\circ} \mathrm{C}$ are showed in Figure 4, the particle are very fine and were found to be $<10 \mathrm{~nm}$. It is evident from the images that the particles are poorly crystalline and agglomerated.

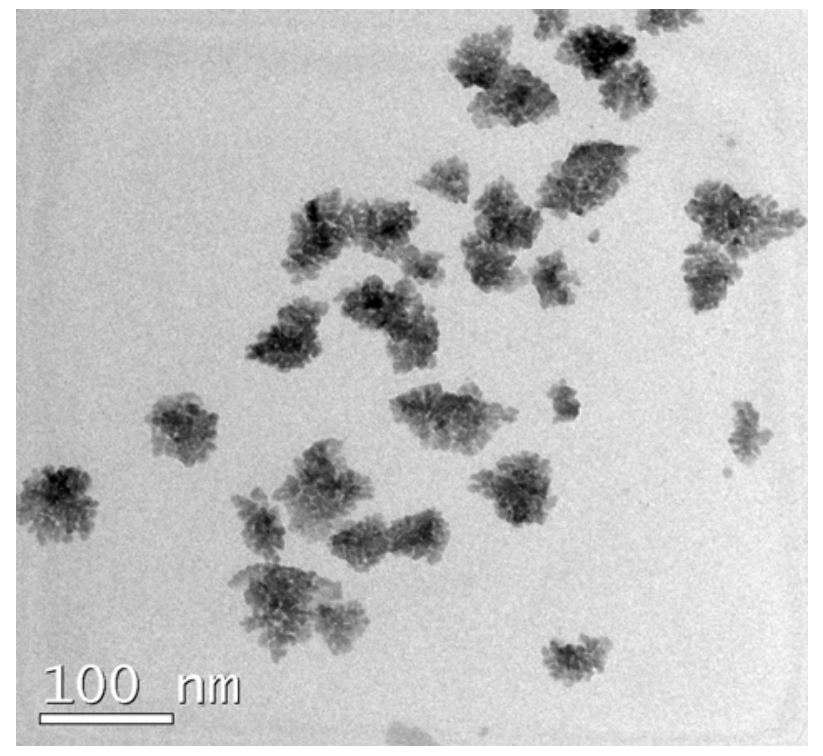

Figure. 4. TEM image of iron oxide hydroxide nano particles 


\section{2. Fluoride adsorption behavior}

In order to investigate fluoride uptake capacity of the iron oxide hydroxide nano particles the experiments were carried out to study the effect of solution $\mathrm{pH}$, contact time and initial fluoride concentration. The experiments were conducted at ambient temperature.

\section{2. 1. Effect of solution $p H$}

Anion adsorption on metal oxide surface is through columbic forces and/or ligand exchange reactions, where the anions displace $\mathrm{OH}^{-}$or $\mathrm{H}_{2} \mathrm{O}$ from the surface (Rabie et al., 1997). The effect of $\mathrm{pH}$ on fluoride removal from aqueous solution by iron oxide hydroxide nano particles was studied in the $\mathrm{pH}$ range of 2.5 to 9 . The fluoride initial concentration was kept $20 \mathrm{mg} / \mathrm{L}$ for all the experiments. Figure 5 shows the effect of solution $\mathrm{pH}$ on fluoride removal efficiency. It was observed that the fluoride uptake capacity of iron oxide hydroxide increased with $\mathrm{pH}$ up to 4, there after it showed decreasing trend with the increase of initial $\mathrm{pH}$. The $\mathrm{pH}_{\mathrm{PZC}}$ of the prepared iron oxide hydroxide sample was found to be 5.3, this value is lower than the reported values for amorphous $\mathrm{FeOOH}$ (Balisterieri and Murray, 1981). Therefore, at $\mathrm{pH}$ lower than $\mathrm{pH}_{\mathrm{PZC}}$ iron oxide hydroxide becomes a strong anion exchanger.

In the present study fluoride adsorption on the surface is coupled with a release of $\mathrm{OH}^{-}$ions, and favored at low $\mathrm{pH}$ values, decrease of adsorption with increase of $\mathrm{pH}(>4)$ may be because of stronger competition of hydroxide ions on adsorbent surface. It was observed that the $\mathrm{pH}$ of the equilibrated solution increased (1.0-1.8) in acidic $\mathrm{pH}$ range, while it decreased(1.0-3.0) when the initial solution was in alkaline range. The fluoride adsorption on iron oxide hydroxide surface is thought to be because of anion exchange at acidic $\mathrm{pH}$ and by van der Waals forces at alkaline $\mathrm{pH}$ ranges. The fluoride adsorption on iron oxide hydroxide surface can be depicted as two step protonation/ligand exchange reaction mechanisms

$$
\begin{aligned}
& \equiv \mathrm{M}-\mathrm{OH}+\mathrm{H}^{+} \leftrightarrow \equiv \mathrm{MOH}_{2}^{+} \\
& \equiv \mathrm{MOH}_{2}^{+}+\mathrm{F}^{-} \leftrightarrow \equiv \mathrm{MF}+\mathrm{H}_{2} \mathrm{O}
\end{aligned}
$$

Which gives the net reaction

$$
\equiv \mathrm{M}-\mathrm{OH}+\mathrm{H}^{+}+\mathrm{F}^{-} \leftrightarrow \equiv \mathrm{MF}+\mathrm{H}_{2} \mathrm{O}
$$

In this model the $\mathrm{pH}$ of the solution after adsorption should increase, which is in agreement with observed changes in equilibrium solution $\mathrm{pH}$.

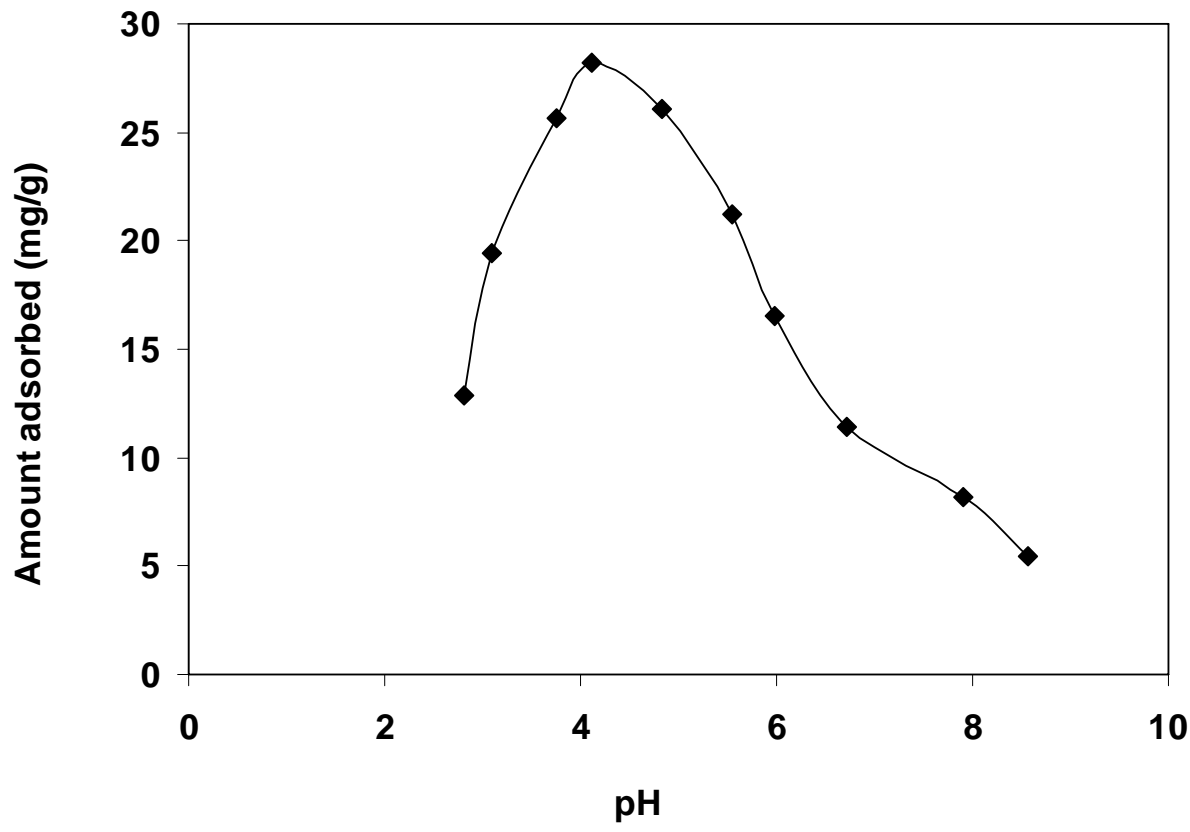

Figure 5. Effect of solution $\mathrm{pH}$ on fluoride adsorption. Conditions:

adsorbent dose: $0.5 \mathrm{~g} \mathrm{~L}^{-1}, \mathrm{~F}^{-}$initial concentration: $20 \mathrm{mg} \mathrm{L}^{-1}$, Temperature: $31^{\circ} \mathrm{C}$. 


\section{2. 2. Effect of time at different initial fluoride concentrations}

Kinetic studies were carried out to see the effect of initial fluoride concentration on the fluoride removal rate. The effect of time factor was studied up to $2 \mathrm{~h}$ at different initial fluoride concentration $(10-30 \mathrm{mg} / \mathrm{L})$. Since material showed maximum fluoride adsorption at $\mathrm{pH} 4$, solution $\mathrm{pH}$ was adjusted to 4 for rest of the experiments. The results given in Figure 6a, show that loading capacity increased from 14.50 to $36.00 \mathrm{mg} / \mathrm{g}$ by increasing initial fluoride concentration from 10 to $30 \mathrm{mg} / \mathrm{L}$ at $\mathrm{pH} 4.0$. The fluoride adsorption on iron oxide nano particles was found to be very fast, almost $90 \%$ of the total adsorption was completed within 30 minutes and the equilibrium was attained within $1 \mathrm{~h}$ at all the studied concentrations.

The pseudo-first order and pseudo-second order adsorption models were used to study the adsorption kinetics of present experimental data. The pseudo-first order adsorption kinetic model is given as

$$
\log \left(q_{e}-q_{t}\right)=\log q_{e}-\frac{k_{1}}{2.303} t
$$

Where $q_{e}$ and $q_{t}$ are the amount of fluoride adsorbed $(\mathrm{mg} / \mathrm{g})$ at equilibrium and at any time $\mathrm{t}(\mathrm{min})$ respectively. The adsorption rate constant $k_{1}$ was determined from the slope of the linear plots of $\log \left(q_{e^{-}} q_{t}\right)$ vs $t$ (Figure 6b).

The pseudo- second-order adsorption kinetic model is given as

$$
\frac{t}{q_{t}}=\frac{1}{k_{2} q_{e}^{2}}+\frac{1}{q_{e}} t
$$

The values of $q_{e}$ (1/slope), adsorption rate constant $k_{2}$ (slope ${ }^{2} /$ intercept) can be obtained by plotting $t / q_{t}$ versus $t$ (Figure $6 \mathrm{c}$ ). The adsorption kinetics constants obtained from the pseudo-first order and pseudo second order models are given in Table 1. Though the regression coefficients for the first order plots were $>0.94$, but the experimental values of fluoride uptake were much less when compared to the actually obtained values. In case of pseudo-second- order model the uptake values were close to the experimental values. Further the regression coefficients were $>0.99$ for the pseudo-second-order model.

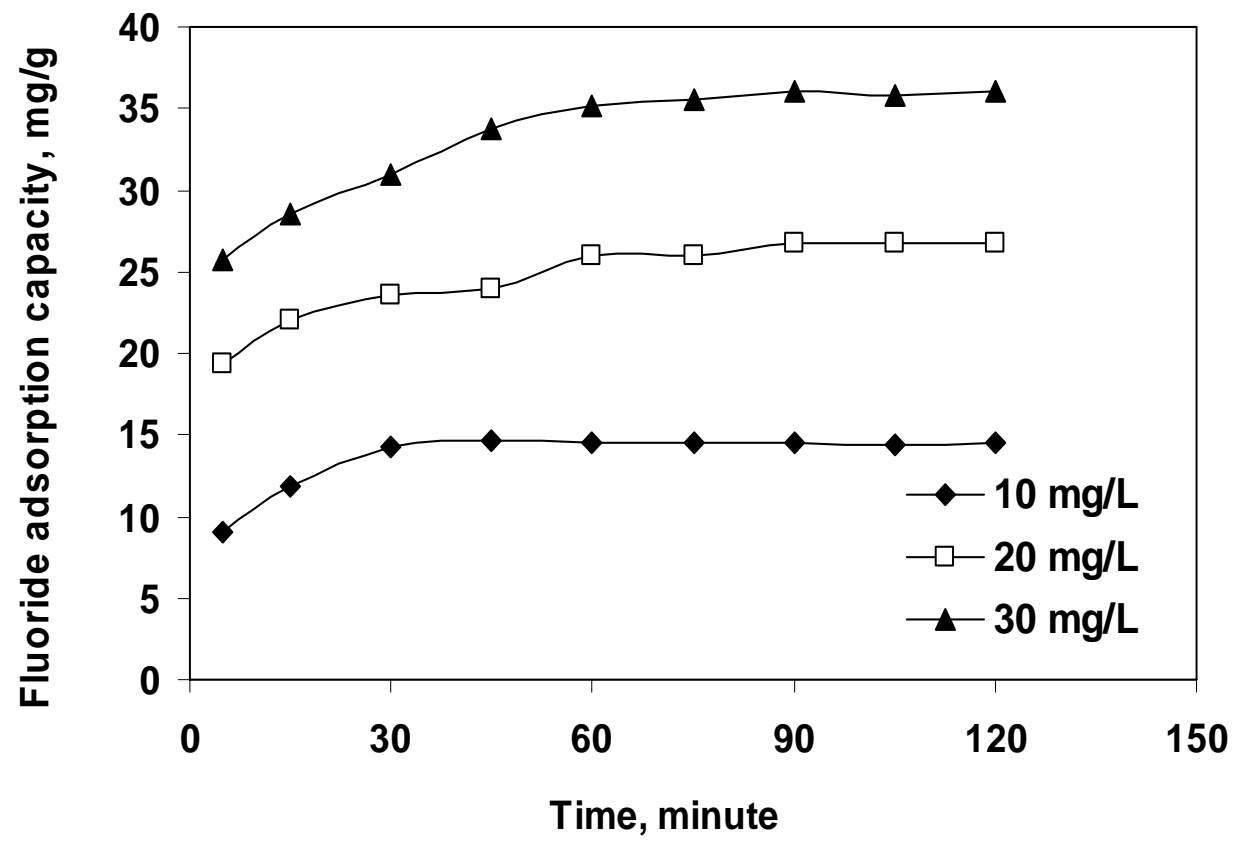

Figure 6a Fluoride adsorption on ferrihydrite nano powder at different fluoride initial concentrations. Conditions : adsorbent dose $0.5 \mathrm{~g} / \mathrm{L}, \mathrm{pH} 4.0( \pm 0.1)$, temperature $31^{\circ} \mathrm{C}$. 


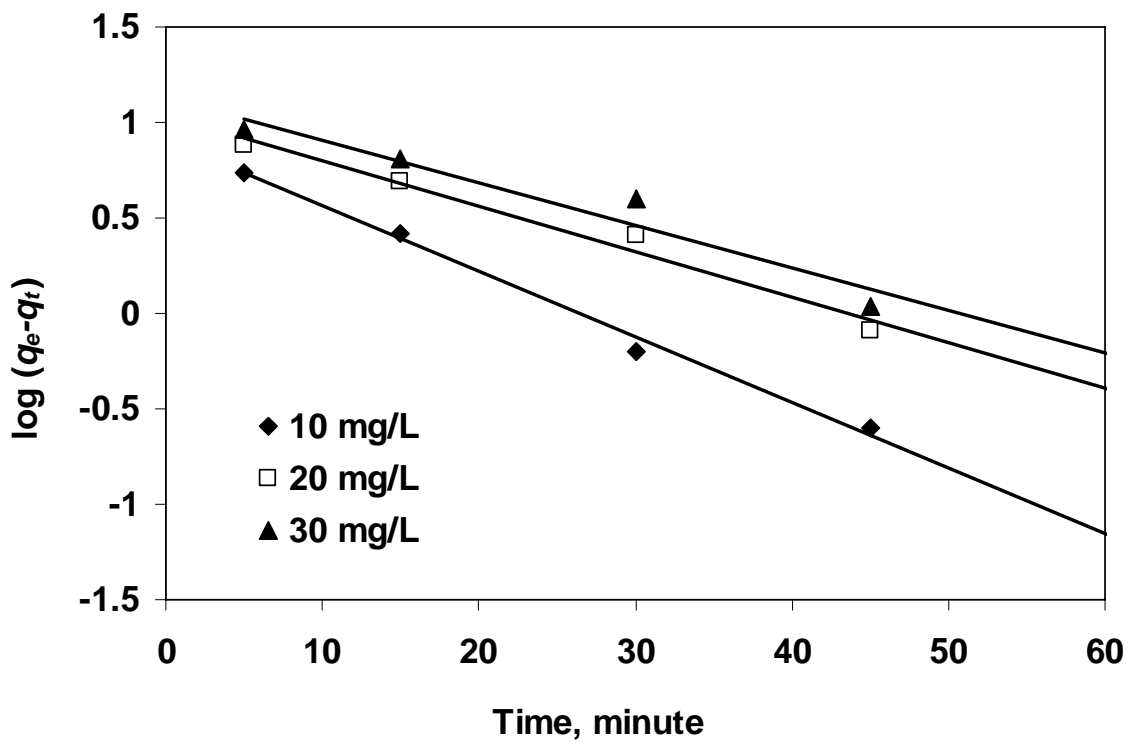

Figure 6b. Pseudo first order kinetic plot for fluoride adsorption (data corresponding to Figure 5a).

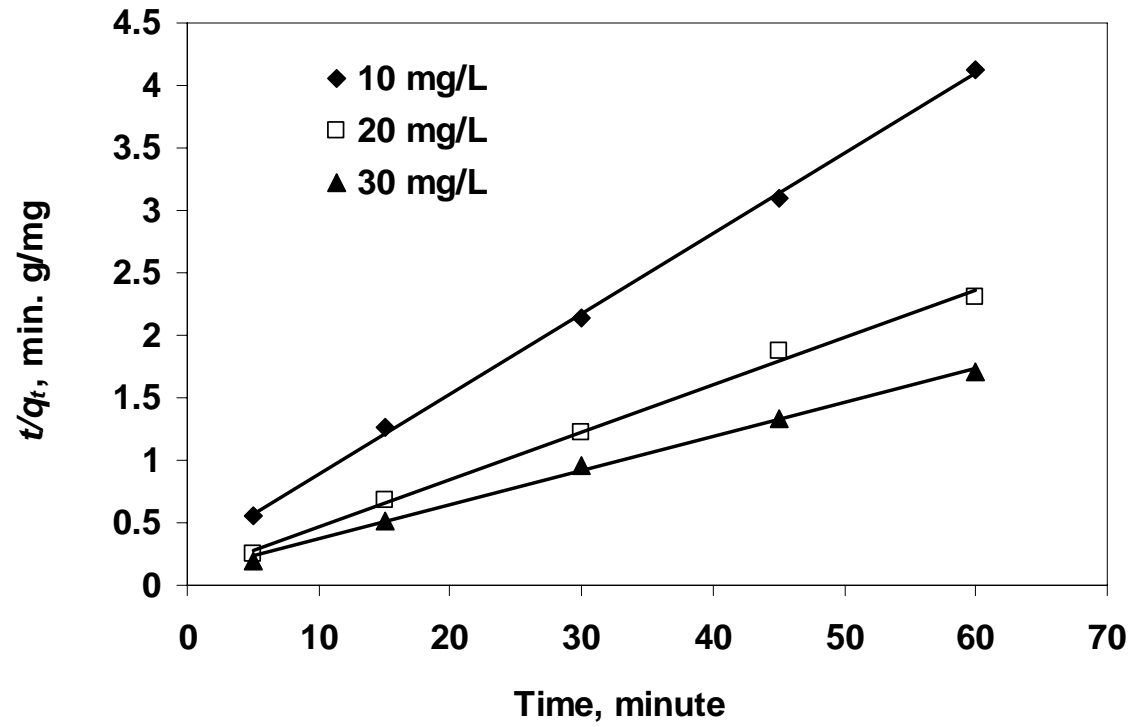

Figure 6c. Pseudo second order kinetic plot for fluoride adsorption (data corresponding to Figure 5a).

Besides the adsorption at the outer surface of the adsorbent, the adsorbate molecules may also diffuse into the interior of the porous adsorbent (Mahramanlioglu et al., 2002). The intraparticle diffusion is the rate controlling factor; uptake of the adsorbate varies with the square root of the time. For the rate constant of intraparticle diffusion the equation can be written as,

$$
q_{t}=k_{i} \sqrt{t}
$$

Where $k_{i}$ is intraparticle diffusion rate constant $\left(\mathrm{mg} / \mathrm{g} \min ^{0.5}\right)$ and $q_{t}$ is the amount of fluoride adsorbed at any time $t(\mathrm{mg} / \mathrm{g})$. This was studied by plotting the amount of the fluoride adsorbed vs. the square root of time (Fig. 6d). A straight line representing the control of sorption by intra particle diffusion is observed. The solute ions diffuse within the pores and capillaries of the metal oxide, as these provide available sites for adsorption. The values of intra particle diffusion rate constants $K_{i}$ were calculated from the slopes of the plots from Fig.6d and were found to be $1.01,1.09$ and $1.74 \mathrm{mg} / \mathrm{g} \mathrm{min}{ }^{0.5}$ for fluoride initial concentrations of 10 , 20 and $30 \mathrm{mg} / \mathrm{L}$ respectively. 


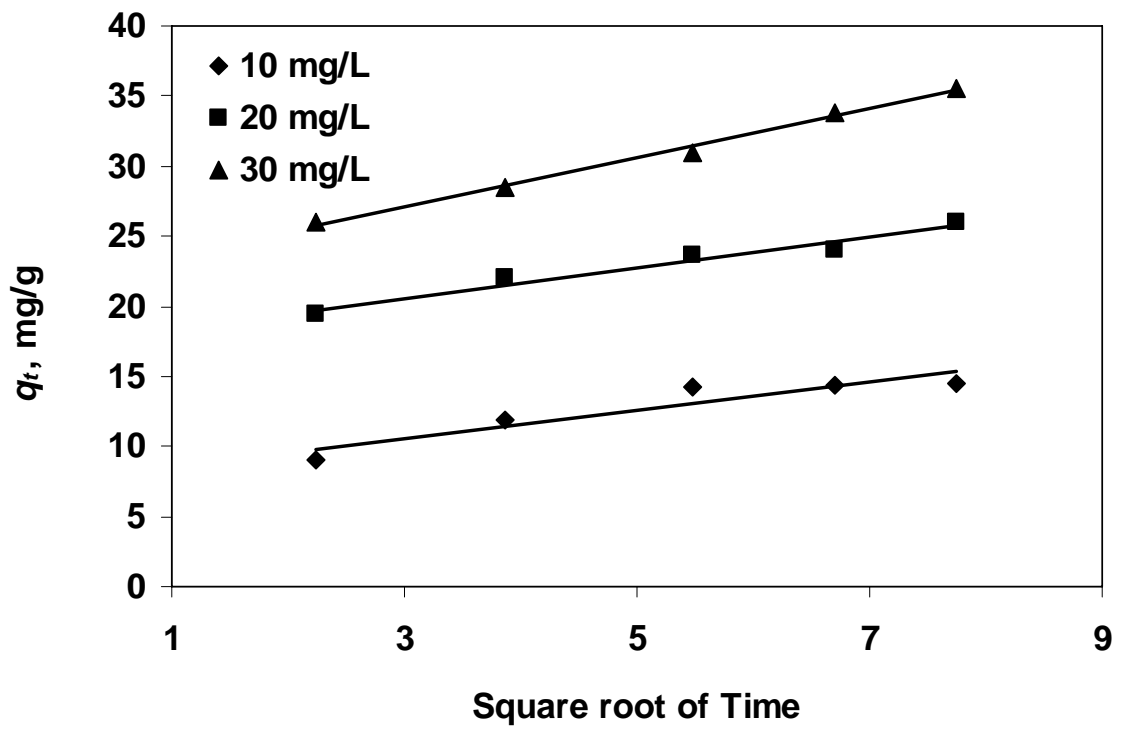

Figure 6d. A plot of amount of fluoride adsorbed versus square root of time for intraparticle diffusion (data corresponding to Figure 5a).

Table 1. kinetic parameters for fluoride adsorption onto iron oxide nano particles at different initial fluoride concentrations.

(Experimentally obtained $q_{e}$ values are 14.5, 26.0 and $36 \mathrm{mg} / \mathrm{g}$ for 10, 20 and $30 \mathrm{mg} / \mathrm{L}$ respectively).

\begin{tabular}{lllllllll}
\hline $\begin{array}{l}\text { Initial } \\
\mathrm{F}^{-} \text {Conc. }\end{array}$ & \multicolumn{2}{l}{ Pseudo-first order } & \multicolumn{3}{l}{ Pseudo-second order } & \multicolumn{3}{l}{ Intra-particle diffusion } \\
\cline { 2 - 8 } $\mathrm{mg} \mathrm{L}^{-1}$ & $\begin{array}{l}k_{1} \\
\left(\mathrm{~min}^{-1}\right)\end{array}$ & $\begin{array}{l}q_{e} \\
(\mathrm{mg} / \mathrm{g})\end{array}$ & $\mathrm{R}^{2}$ & $\begin{array}{l}k_{2}(\mathrm{~g} / \mathrm{mg} / \\
\mathrm{min}) \times 10^{-2}\end{array}$ & $\begin{array}{l}q_{e} \\
(\mathrm{mg} / \mathrm{g})\end{array}$ & $\mathrm{R}^{2}$ & $\begin{array}{l}k_{i} \\
\mathrm{mg} / \mathrm{g} \mathrm{min} \min ^{1 / 2}\end{array}$ & $\mathrm{R}^{2}$ \\
\hline 10 & 0.789 & 8.03 & 0.96 & 1.68 & 15.57 & 0.99 & 1.01 & 0.87 \\
20 & 0.054 & 10.92 & 0.97 & 1.49 & 26.52 & 0.99 & 1.09 & 0.96 \\
30 & 0.051 & 13.55 & 0.93 & 0.81 & 36.00 & 1.0 & 1.74 & 0.99 \\
\hline
\end{tabular}

\subsubsection{Isotherm Study}

The experimental data obtained for different initial fluoride concentrations (10 to $30 \mathrm{mg} / \mathrm{L}$ with an interval of 5) at constant temperature and $\mathrm{pH}$ were plotted in a linearised form of Langmuir and Freundlich sorption isotherms as given below:

$$
\begin{aligned}
& \frac{C_{e}}{q_{e}}=\frac{1}{Q_{o} b}+\frac{C_{e}}{Q_{o}} \\
& \log q_{e}=\log K_{F}+\frac{1}{n} \log C_{e}
\end{aligned}
$$

where $C_{e}$ is equilibrium concentration $(\mathrm{mg} / \mathrm{L}), q_{e}$ is the amount adsorbed at equilibrium $(\mathrm{mg} / \mathrm{g}), Q_{o}$ is sorption capacity for Langmuir isotherm and ' $b$ ' is an energy term which varies as a function of surface coverage strictly due to variations in the heat of adsorption. The Freundlich constant, ' $n$ ' indicates the degree of favorability of adsorption and $K_{F}$ is the isotherm constant (Ruthven 1984). The adsorption data of fluoride on iron oxyhydroxide fitted to both Langmuir and Freundlich isotherm models as shown in Fig. $7 \mathrm{a}$ and $7 \mathrm{~b}$. The calculated isotherm parameters along with correlation coefficients are given in Table 2 . The magnitude of the Langmuir constant ' $b$ ' has small value $(0.12 \mathrm{~L} / \mathrm{mg})$, which indicates a low heat of adsorption. The " $n$ " value indicates the bond strength between adsorbate and adsorbent and heterogeneous nature of the surface. The fluoride loading capacity calculated from Eq(3) was found to be $62.89 \mathrm{mg} / \mathrm{g}$. This value is much higher than the reported values for nano AlOOH $(3.259 \mathrm{mg} / \mathrm{kg})$. The Langmuir adsorption capacity of nano iron oxide hydroxide is much higher than the reported values for fluoride in the literature (Table .3). 
Table 2. Isotherm parameters for Langmuir and Freundlich Models

\begin{tabular}{cccccc}
\hline \multicolumn{2}{c}{ Langmuir isotherm } & \multicolumn{3}{c}{ Freundlich isotherm } \\
\hline $\begin{array}{c}Q_{o} \\
(\mathrm{mg} / \mathrm{g})\end{array}$ & $b$ & $\mathrm{R}^{2}$ & $K_{F}$ & $n$ & $\mathrm{R}^{2}$ \\
\hline & & & & & \\
62.89 & 0.10 & 0.99 & 7.73 & 1.62 & 0.99 \\
\hline
\end{tabular}

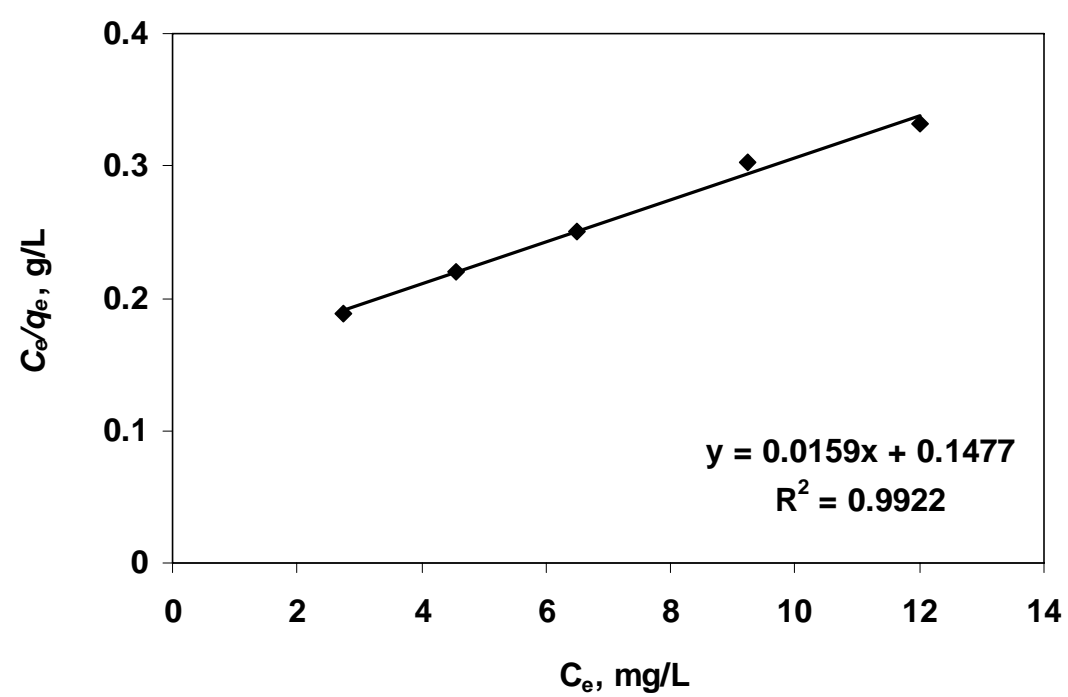

(a)

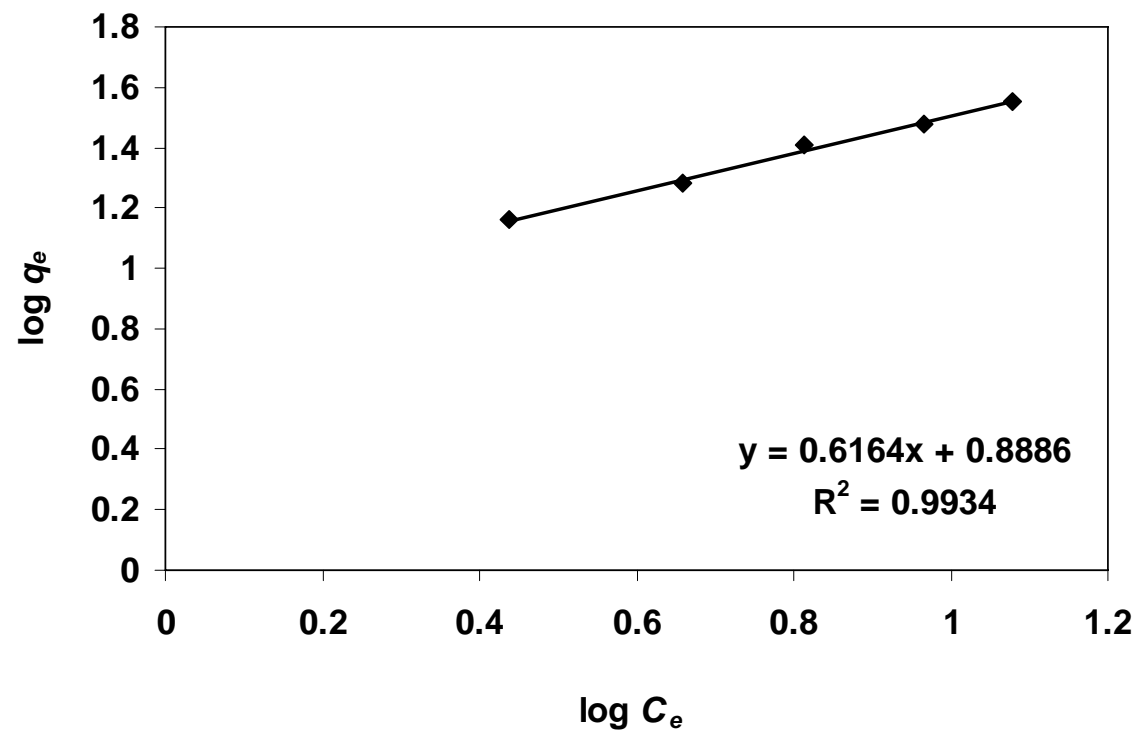

(b)

Figure 7. Adsorption isotherms on iron oxyhydroxide nano particles. (a) Langmuir isotherm plot (b) Freundlich isotherm plot.. 
Table 3 Langmuir fluoride adsorption capacities of different synthetic metal oxide samples.

\begin{tabular}{|c|c|c|c|}
\hline S. No & Adsorbent & $\begin{array}{l}\text { Langmuir adsorption } \\
\text { capacity }(\mathrm{mg} / \mathrm{g})\end{array}$ & Reference \\
\hline 1. & Crystalline $\mathrm{Fe} / \mathrm{Al}$ oxides & 17.70 & Biswas et al., 2007 \\
\hline 2. & $\begin{array}{l}\text { Aluminium type super para } \\
\text { magnetic adsorbent }\end{array}$ & 38.00 & Chiung et al., 2006 \\
\hline 3. & Magnetic chitosan particle & $20-23$ & Wei Ma et al., 2006 \\
\hline 4. & $\begin{array}{l}\text { Hydrous manganese-oxide } \\
\text { coated alumina }\end{array}$ & 07.09 & Teng et al., 2009 \\
\hline 5. & Mesoporous alumina & 14.26 & Grace et al., 2010 \\
\hline 6. & Nano Iron oxyhydroxide & 62.89 & Present study \\
\hline
\end{tabular}

\section{3. Fluoride desorption studies}

The desorption study can give a clear idea about the mechanism of adsorption along with the stability of the adsorbent for further use. The sodium hydroxide solution was selected as the desorption reagent since its effectiveness has been proven by many previous studies (Zhang et al., 2005, Xiaomei et al., 2007). Desorption experiments were conducted by taking (25mg/g) fluoride loaded sample in poly propylene bottles and the solutions at different $\mathrm{pH}(3-12)$ were selected as the desorption reagents. The samples were agitated for 8 hours in a water bath shaker at room temperature. Desorption of fluoride from loaded iron oxyhydroxide surface at different $\mathrm{pH}$ are presented in Fig. 8. Evidently desorption efficiency of the solution varied with its $\mathrm{pH}$ value. Initially there was no release of fluoride up to $\mathrm{pH} 9$, there after it started showing fluoride desorption. It was observed that at $\mathrm{pH} 12.21$ (corresponding to $\mathrm{NaOH}$ strength of $0.016 \mathrm{M}$ ) around $84 \%$ desorption efficiency was achieved. Further rise of solution $\mathrm{pH}$ did not show much improvement in desorption efficiency.

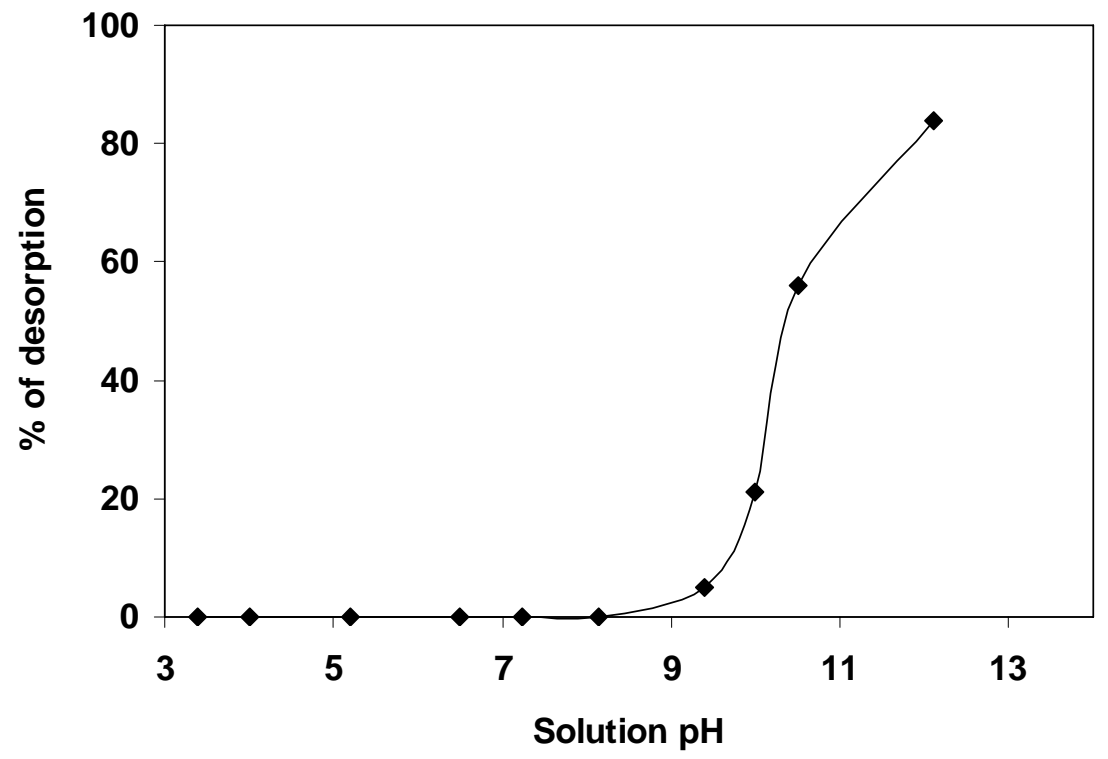

Figure 8. Desorption studies of fluoride loaded iron oxide hydroxide at different $\mathrm{pH}$.

\section{Conclusions}

From this study following conclusions were drawn:

1. Iron oxide hydroxide nano particles were prepared by water in oil microemulsion method by taking non toxic, non ionic surfactant span 80 along with hexanol and $\mathrm{FeCl}_{3}$ solutions as oil and aqueous medium.

2. The TEM analysis of the sample revealed that the particles are poorly crystalline and particle size is in the range of 5-10 $\mathrm{nm}$. As synthesized powder obtained by microemulsion method showed 2 lines ferrihydrite like structure in XRD.

3. The nano-iron oxide hydroxide performed well for fluoride removal from aqueous solutions. Its adsorption kinetics are very fast and equilibrium was attained with in 1 hour. The results of kinetic modeling show that the pseudo second order kinetic model was better described the time effect on the fluoride adsorption when compared to the first order and intraparticle diffusion models. 
4. This study confirms that the iron oxide hydroxide nano particles are suitable adsorbents for fluoride removal from aqueous solutions. The equilibrium data fitted to both Langmuir and Freundlich isotherm models and showed high Langmuir monolayer adsorption capacity $(62.89 \mathrm{mg} / \mathrm{g})$.

\section{Nomenclature}

$C_{i} \quad$ Initial adsorbate concentration, $\mathrm{mg} / \mathrm{L}$

$C_{e} \quad$ Concentration of adsorbate at equilibrium, $\mathrm{mg} / \mathrm{L}$

$C_{A} \quad$ Adsorbent concentration, $\mathrm{g} / \mathrm{L}$

$X \quad$ Adsorption capacity, $\mathrm{mg} / \mathrm{g}$

$q_{e} \quad$ Adsorption capacity at equilibrium, $\mathrm{mg} / \mathrm{g}$

$q_{t} \quad$ Adsorption capacity at time $\mathrm{t}, \mathrm{mg} / \mathrm{g}$

$k_{1} \quad$ First order rate constant, $\min ^{-1}$

$t \quad$ Time, minute

$k_{2} \quad$ Second order rate constant, $\mathrm{g} / \mathrm{mg} / \mathrm{min}$

$R^{2} \quad$ Regression co-efficient

$k_{i} \quad$ Intra-particle diffusion rate constant, $\mathrm{mg} \mathrm{g} \min ^{0.5}$

$Q_{o} \quad$ Langmuir adsorption capacity, $\mathrm{mg} / \mathrm{g}$

$b \quad$ Langmuir equilibrium coefficient, $\mathrm{L} / \mathrm{g}$

$K_{F} \quad$ Freundlich constant

$n \quad$ term related to adsorption intensity

\section{References}

Amit Bansiwal, Pradnya Pillewan, Rajesh B., Sadhana R., 2010. Copper oxide incorporated mesoporous alumina for defluoridation of drinking water. Microporous and Mesoporous Materials. Vol. 129, pp. 54-61.

APHA., 1985. Standard methods for the examination of water and wastewater, $15^{\text {th }}$ Ed., American Public Health Association, America Water Works Association and Water Pollution Control Federation. Washington D.C.

BIS Bureau of Indian Standards Drinking water-specification 2003. IS:10500, New Delhi.

Balistrieri L.S and Murray, J.W., 1981. The surface chemistry of goethite (alpha FeOOH) in major ion seawater. Journal of American Science. Vol. 281, pp. 788-806

Biswas K., Bandhoyapadhyay, D. and Ghosh, U.C., 2007. Adsorption kinetics of fluoride on iron (III)-zirconium(IV) hybrid oxide. Adsorption. Vol.13, pp. 83-94.

Biswas K, Saha S. K. and Ghosh U. C., 2007. Adsorption of fluoride from aqueous solution by a synthetic Iron(III)-Aluminum(III) mixed oxide. Industrial Engineering Chemistry Research. Vol. 46, pp. 5346-5356.

Cheung C. W., Porter J. F., Mckay G., 2001. Sorption kinetic analysis for the removal of cadmium ions from effluents using bone char. Water Research. Vol. 35, pp 605-612.

Chiung-Fen Chang, Pei-Hsuan Lin, WolfgangHoll, 2006. Aluminum-type super paramagnetic adsorbents: synthesis and application on fluoride removal. Colloids and Surfaces A: Physicochem. Eng. Aspects, Vol. 280, pp. 194-202.

Choi W. W., Chen K. K, 1979. The removal of fluoride from water by adsorption. Water Technology, Vol.10, pp. 562-570.

Dghoughi L., Elidrissi B., Bernede C., Addou M., Alaoui Lamrani M., Regragui M., Erguig H., 2006. Physico-chemical, optical and electrochemical properties of iron oxide thin films prepared by spray pyrolysis. Applied Surface Science, Vol. 253, pp. 1823-1829.

Grace Lee, Chao Chen, Seung-Tae Yang, Wha-Seung Ahn, 2010. Enhanced adsorptive removal of fluoride using mesoporous alumina. Microporous and mesoporous Materials. Vol. 127, pp. 152-156.

Hichour M., Persin F., Sandeaux J., Gavach C., 2000. Fluoride removal from waters by Donnan dialysis. Separation and Purification Technology. Vol. 18, pp. 1-11.

Jin Qiu, $\mathrm{Ru}$ Yang, Min Li, Nan Jiang, 2005. Preparation and characterization of porous ultrafine $\mathrm{Fe}_{2} \mathrm{O}_{3}$ particles. Materials Research Bulletin. Vol. 40 pp.1968-1975.

Jiye fang, Amar Kumbhar, Weilie L. Zhou, Kevin L. Stokes, 2003. Nano-needles of maghemite iron oxide prepared from a wet chemical route. Materials Research Bulletin. Vol. 38 pp. 461-467.

Lin Chen, Hai-Xia WuTing-Jie Wang, Yong Jin, Yu Zhang, Xiao-Min Dou, 2009. Granulation of Fe-Al -Ce nano adsorbent for fluoride removal from drinking water by spray coating on sand in a fluidized bed. Powder technology. Vol. 193, pp. 59-64.

Lou, F. and Inoue K., 2004. The removal of fluoride ion by using metal(III)-loaded amberlite resins. Solvent Extraction and Ion Exchang. Vol. 22, pp. 305-322.

Mahramanlioglu M., Kizilcikli I., Bicer I. O., 2002. Sorption of fluoride from aqueous solution by acid treated spent bleaching earth. Journal of Fluorine Chemistry. Vol. 115, pp. 41-47. 
Markus Niederberger, 2007. Nonaqueous Sol-Gel routes to metal oxide nanoparticles. Account of Chemical Research. Vol. 40, No.9, pp 793-800.

Ndiaye P.I., Moulin P., Dominguez L., Millet J.C., Charbit F., 2005. Removal of fluoride from electronic industrial effluent by RO membrane separation. Desalination. Vol. 173, pp.25-32.

Petrova O. S., Gudilin E. A., Chekanova A. E., Suzdalev I. P and Tret yakov Yu. D., 2006. Doklady Chemistry. Vol.410 part 2 , 174-177. DOI: 10. 1134/S001250080610003X

Rabie H. R., Helou D. Weber M. E. and VeraJ. H., 1997. Comparison of the titration and contact methods for the water solubilization capacity of AOT reverse micelles in the presence of co-surfactant. Journal of Colloid Interface Scence. Vol. 189, pp. 208.

Raichur A.M. and Basu M.J., 2001. Adsorption of fluoride onto mixed rare earth oxides. Separation and Purification Technology. Vol. 24 pp. 121-127.

Ruthven D. M., Principles of sorption and sorption processes, 1984. Chapter. 6, John Wiley \& Sons publishers, New York.

Sara Eriksson, Ulf Nylen, Sergio Rojas, Magali Boutonnet, 2004. Preparation of catalysts from microemulsions and their applications in heterogeneous catalysis. Applied Catalysis A: General. Vol. 265, pp. 207-219.

Schoeman J. J., Botha G. R., 1985. Evaluation of the activated alumina process for fluoride removal and some factors influencing this performance. Water South Africa. Vol. 11, No. 1, pp 25-32.

Shu-Guang wang, Yue ma, Yi-Jing Shi and Wen-Xin Gong, 2009. Defluoridation performance and mechanism of nano-scale aluminum oxide hydroxide in aqueous solution. Journal of Chemical Technology and Biotechnology. Vol. 84, pp 1043-1050.

Shao-Xiang Teng, Shu-Guang wang, Wen-Xin Gong, Xian-Wei Liu, Bao-Yu Gao, 2009. Removal of fluoride by hydrous maganese oxide-coated alumina: Performance and mechanism. Journal of Hazardous Materials. 168 1004-1011.

Song Ge, Xiangyang Shi Kai Sun, Changpeng Li Ctirad Uher James R. Baker, Jr., Mark M. Banaszak Holl and Bradford G. Orr, 2009. Facile hydrothermal synthesis of iron oxide nanoparticles with tunable magnetic properties. Journal of Physical Chemistry C. Vol.113, No.31, pp 13593-13599.

Sujana M.G., Soma G., Vasumathi N., Anand S., 2009. Studies on fluoride adsorption capacities of amorphous Fe/Al mixed hydroxides oxides from aqueous solutions. Journal of Fluorine Chemistry. Vol. 130, No.8, pp. 749-754.

Wei Ma, Fei- Qun Ya, Mei Han, Ren Wang, 2007. Characteristics of equilibrium, kinetics studies for adsorption of fluoride on magnetic-chitosan particle. Journal of Hazardous Materials. Vol. 143, pp. 296-302.

Wei Ma, Fei-Qun ya, Mei Han, Ren Wang, 2006. Characteristics of equilibrium, kinetics studies for adsorption of fluoride on magnetic-chitosan particle. Journal of Hazardous Materials. Vol. 143, pp. 296-302.

WHO 2004. Guidelines for drinking water quality, 3rd edn. World Health Organization, Geneva.

WHO (World Health Organisation ), 1996. Guidelines for drinking water quality, Vol.2. Health criteria and other supporting information. World Health Organisation. Geneva $2^{\text {nd }}$ Ed., pp. 231-237.

Wu Y. C., Nitya A., 1979. Water defluoridation with activated alumina. Journal of Environmental Engineering. ASCE Vol. 105, pp 357-367.

www.unicef.org/wes/files/fluoride.pdf. Fluoride in water: An overview, information supply by UNICEF India.

Xiaoli Zhao, Jieming Wang, Fengchang Wu, Thanh Wang, Yaqi Cai, Yali Shi, Guibin Jiang., 2010. Removal of fluoride from aqueous media by $\mathrm{Fe}_{3} \mathrm{O}_{4} @ \mathrm{Al}(\mathrm{OH})_{3}$ magnetic nanoparticles. Journal of Hazardous Materials. Vol.173, pp. 102-109.

Yamaura M., Camilo R. L., Sampaio L. C., Mac^edo M. A., Nakamura M., and Toma H. E., 2004. Preparation and characterization of (3-aminopropyl)triethoxysilane-coated magnetite nanoparticles. Journal of Magnetism and Magnetic Materials. Vol. 279, No. 2-3, pp. 210-217,

Yuan-hu Zhang, Yao Cheng, Feng Bao, Yuan-Sheng Wang, 2006. Synthesis and magnetic properties of $\mathrm{Fe}_{3} \mathrm{O}_{4}$ nanoparticles. Material Research bulletin. Vol. 41, pp. 525-529.

Balek V. and Subrt J., 1995. Thermal behaviour of iron (III) oxide hydroxides. Pure \& Applied Chemistry. Vol. 67, No. 11, pp. 1839-1842,

\section{Biographical notes}

M. G. Sujana has been working as a senior scientist at Institute of Minerals and Materials Technology (CSIR), Bhubaneswar, India. Her field of work is related to environmental impact assessment and toxic contaminant removal studies from water and waste waters. She has been contributing to basic and applied research in the field of water treatment through several industry and govt. sponsored projects and technical publications. Her research interests also include development of novel sorbents by different methods and their applications in drinking water treatment

Swagatika Mohanty, after obtaining her masters degree in physics has been working at Institute of Minerals and Materials Technology (CSIR), Bhubaneswar, India. She is specialized in electronics and has experience working with sophisticated analytical instruments. Prior to joining the institute, she was working as junior research fellow at Defence Research Development Organization, Chandipur, India. Her interests are on material characterization.

Received August 2010

Accepted October 2010

Final acceptance in revised form October 2010 